\title{
ASSESSMENT OF INDIVIDUALS' ATTITUDE, KNOWLEDGE AND ANXIETY TOWARD COVID-19 AT THE FIRST PERIOD OF THE OUTBREAK IN TURKEY: A WEB BASED CROSS-SECTIONAL SURVEY
}

\author{
Duygu AYHAN BASER ${ }^{1}$, RAZIYE GÜMÜŞTAKIM ${ }^{2}$, MURAT CEVIK ${ }^{3}$, and EKREM \\ BASARA $^{4}$ \\ ${ }^{1}$ Hacettepe University Faculty of Medicine \\ ${ }^{2}$ Kahramanmaras Sutcu Imam University - Avsar Campus \\ ${ }^{3}$ Güdül Family Health Center, Güdül ANKARA \\ ${ }^{4}$ Ministry of Health Ankara City Hospital
}

April 28, 2020

\begin{abstract}
Objective The aim of this study is to evaluate the attitude, knowledge and anxiety status of individuals about COVID-19 at the first period of the outbreak. Methods This was an observational study carried out in Turkey. An online semi-structured questionnaire was developed by using google forms and the link of the questionnaire was sent through emails, WhatsApp and other social media to the contacts of the investigators between 20th March 2020 and 25th March 2020. The questionare contained 21 questions and Beck anxiety scale. Results 1070 people were included in the study. Approximately one fifth of the participants had no idea about treatment and immunization against COVID19. According to the categorization of Beck Anxiety Inventory scores $8.6 \%$ showed severe anxiety symptoms. Anxiety levels of women, healthcare workers and those with psychiatric illness were higher $(\mathrm{p}<0.05)$. It was observed that women, healthcare professionals, those with chronic diseases, and those with moderate to severe anxiety used the medical facemask more frequently $(\mathrm{p}<0.05) .73 \%$ of the participants thought that they fully implemented the proposed measures; $25.2 \%$ of the them stated that population did not take any measures for the COVID-19. Conclusion: According to the results of the study individuals usually had better awareness and positive attitudes towards COVID 19 pandemic, but there were also things that needed improvement. The community anxiety rates in the early stages of the epidemic with low case rates also reveal that measures should be taken in this regard.
\end{abstract}

\section{Hosted file}

Manuscript COV \selectlanguage\{polish\}İselectlanguage\{english\}D19 ANX.docx available at https: //authorea.com/users/310405/articles/446373-assessment-of-individuals-attitude-knowledgeand-anxiety-toward-covid-19-at-the-first-period-of-the-outbreak-in-turkey-a-web-based-crosssectional-survey 